\title{
DESIGN OF HOLLOW SECTION OVERLAP JOINTS WITH REINFORCING RIB PLATE. JOINT RESISTANCE
}

\begin{abstract}
J. BRÓDKA ${ }^{1}$
These joints are used when the designer and contractor anticipate difficulties during the construction of overlap joints. They were not included in the PN EN 1993-1-8 in full scale. Resistance assessment of such joints is presented in accordance with standard rules. The results were compared with the experimental studies carried out at the "Mostostal" Centre; while the former research activities and the legitimacy of the proposed method of assessing the resistance of these joints was confirmed. This is an example of an overlap joint calculation.
\end{abstract}

Keywords: resistance, assessment, overlap joint

\section{INTRODUCTION}

The trusses joints made of rectangular hollow sections with a reinforcing rib plate between the braces have not been examined as extensively as the standard shaped welded joints under CIDECT and IIW , because their widespread use is not recommended. This is the result of an increase in required performance due to the cutting and welding operations. Therefore, there is a lack of basic information about their resistance and the shaping of joints. These joints are simple and necessary in some designs. Joints with reinforcing rib plate are useful when:

a) support joints are specifically designed to slightly overlap

b) experiencing technical difficulties due to laying welds in underlying areas of CHS made joints.

c) groove welds between brace members are omitted,

\footnotetext{
${ }^{1}$ Professor Emeritus in Bialystok University of Technology, ul .Wiejska 45, 15-351 Białystok, e-mail: jan.brodka@gmail.com
} 
d) there is a small overlap of the brace members which is not recommended by EN 1993-1-8, and in spite of occurrences require strength assessment.

The lack of publicly available information about the shaping of such joints and their resistance has prompted the author to use the results of an experimental study of such elements to broadly discuss the basic situations that a designer may have to face during their professional career. No published research reports [10], [12] areavailable. However, the development of knowledge regarding the range of constructions made of hollow sections has made it possible to formulate rules for resistance assessment of these joints based on recommendations contained in EN 1993-1-8 [5]. Joint shapes. In the case of trusses made of hollow square sections, basic joint shapes with a reinforcing rib between braces are visible in Figure 1. In relatively rare cases the rectangular hollow sections are also used, but the geometry of the joints remains the same. Most of the time braces are the same width and height. Depending on the kind of a truss used, the incline angles of the braces' axis differ. Joints made of circular hollow sections are shaped similarly (sometimes with minor changes).

Fig. 1a shows the solution of the joints when the height $h_{1}$ of the braces is less than the height of the chord, in which case the eccentricity is generally negative and equal $-0,35 \mathrm{~h}_{0} \leq \mathrm{e} \leq-0,55 \mathrm{~h}_{0}\left(\mathrm{~h}_{0}-\right.$ the height of the chord) or $-0,35 \mathrm{~d}_{0} \leq \mathrm{e} \leq-0,55 \mathrm{~d}_{0}$ ( $\mathrm{d}_{0}$ - the diameter of the chord). In contrast, Fig. $1 \mathrm{~b}$ shows an example of a joint where the height of the chord and braces are nearly identical. In turn, in Fig.1c the solution which uses an equal height for the braces and the chord is presented. In order for the overlap of the braces to not be too high the eccentricity should be positive and in the range of 0 $\leq \mathrm{e} \leq 0,25 \mathrm{~h}_{0}$.

The thickness of the rib depends on the values of the forces in the braces and is usually calculated as $1,5 \mathrm{t}_{0} \leq \mathrm{t}_{\mathrm{p}} \leq 2 \mathrm{t}_{0}$ but at least $10 \mathrm{~mm}$ ( $\mathrm{t}_{0}$ - the wall thickness of the chord).

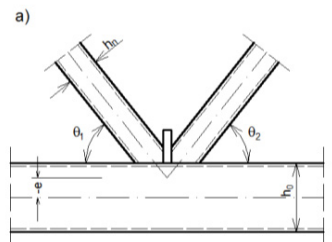

b)

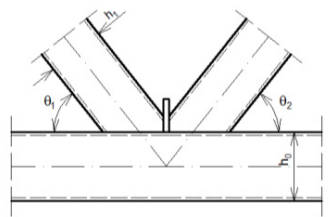

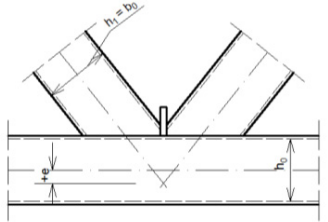

Fig. 1. Joints of trusses made of rectangular hollow sections with reinforcing rib plate 
The joint solutions presented in Fig. 1 are appropriate in the case of the lower chord. Although the upper chord is inclined, its geometry is the same. As can be easily seen in the three cases, the rib is typically placed not axially towards the point of intersection of the braces, but shifted in the direction of the brace which is inclined at a lesser angle to the chord's axis, so that the cutting length of braces on both sides of the rib is the same.

The types of joints presented in Fig. 1 are used in cases with pressing concerns related to steel fabrication with regard to the correct execution of butts or filled welds, especially when overlapping occurs. During manufacturing the truss elements are placed on the stage and joined using the field welds. In that situation the welds are not placed under the overlapping brace.

Such a procedure is allowed in EN 1993-1-8. However, in braces carrying large tensile forces it can be dangerous, because the stresses in welds can exceed the limits determined in EN 1993-8 [5]. This is a difficult situation to assess during the first design. Placing the welds on the overlapped and overlapping lengths of welds close to each other should be avoided because of the danger related to welded metal occurrence of unwanted shrink stresses.

The placing of the overlaps in the joints without ribs is done by cutting a window in the overlapping braces. This proves excessively difficult in case of joints made of circular hollow sections. All these difficulties can be avoided by designing joints with rib plates.

Around the perimeters of the braces, butt or fillet welds are performed in their cases, when their arrangement is possible in the correct way; that is, when the difference of width of the joining walls is big enough. When the arrangement is possible and the joining walls are wide enough, butt and fillet welds are performed around the braces' parimeter. At other times, fillet welds are applied on the flat areas of the circular hollow section and groove welds on the remaining sections.

Creating a joint made of circular hollow sections should be considered, in which the diameters of the braces in the splice with the chord same, when $d_{1}=d_{0}\left(d_{1}\right.$ - diameter of the brace and $d_{0}$ diameter of the chord). This is shown in Fig. 2. It is impossible to execute a butt or fillet weld along the entire length of the connecting point between the brace and the chord, as it is in the length near the plane perpendicular tothe rib which is located in the axis of the chord where the brace takes the form of a sharp beak after cutting along a spatial curve. The tip of this length must be cut so that it is possible to arrange the fillet weld at the desired thickness. In Fig. 2 the geometry of the splice is shown as a straight line parallel to the chord. 


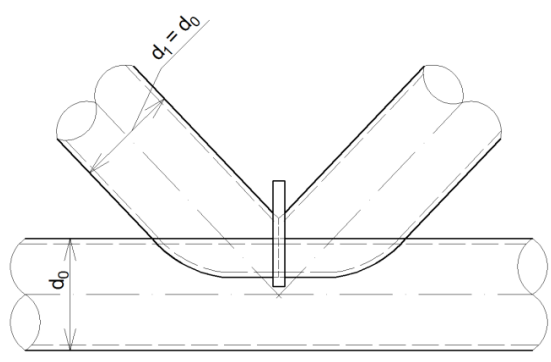

Fig. 2. Typical joint made of circular hollow sections with the reinforcing rib

In the case of the splices between the braces being made of circular and rectangular hollow sections, and in the case of splicing the braces with the chord of the same width or diameter, the thickness of the groove welds obtained is too small in relation to the thickness required to transfer the forces between the components. Braces should be additionally chamfered or reinforcing ribs should be applied according to Fig. 1 or Fig. 2. The solutions presented in Fig. 1 and Fig. 2 are the model jointslocated the middle of a truss or near the internal or external columns. Examples of such joints are shown in Fig. 3 to Fig. 7. Fig. 3 shows the most common joints in the middle of the span of trusses. In this case, sections of the chord have a large size in comparison to braces. Similarly the support of two trusses on a middle column is resolved, but the braces are larger in size. In this situation it is worth designing additional rib between the end plates to lead to a vertical transfer reaction at the head of the column. The extreme post of the truss is made up of a small channel section attached to the support joint's end plate. (Fig. 4). The screws placed at the bottom of the chord secure the truss prior to shifting in a perpendicular plane. The thickness of the head plate is fixed, as in the case of splices subjected to tension forces.

a)

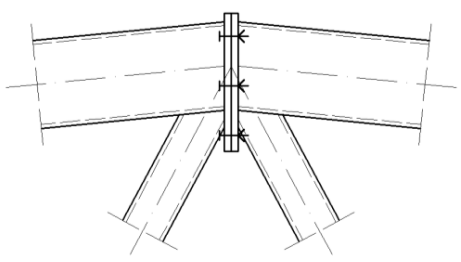

b)

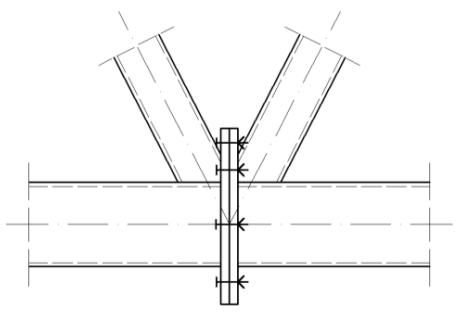

Fig. 3. Trusses joints in the middle of the span 


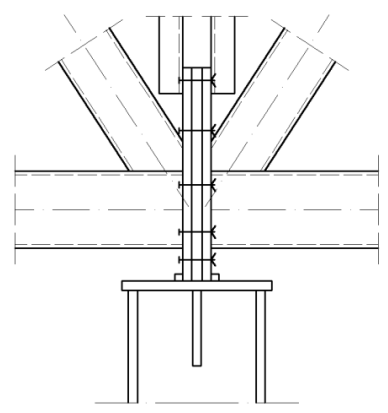

Fig. 4. Support of two trusses on a middle column

Fig. 5 shows several trusses joint solutions, in which the support joint is designed at the upper chord level. Although in Fig. 5c and 5d there are no ribs between braces, the cutting plane of the joining elements is the same as in Fig. 1. On the other hand, Fig. 6 presents a joint with a post based on the column at a lower chord level. The field joints are designed using the shapes shown in Fig. 3 and columns are typically made of I-sections. The vertical reaction is transmitted to a table welded to a column, and a horizontal component of the force in a top joint by means of tension bolts.

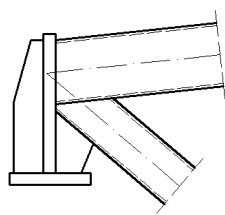

c)

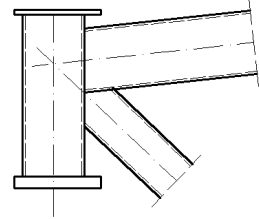

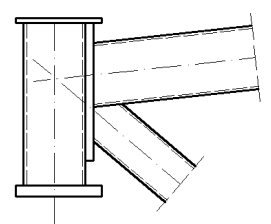

d)

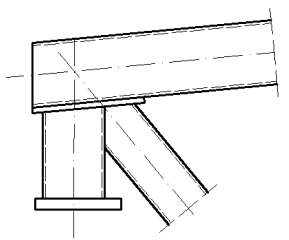

Fig. 5. Trusses joints in the level of the upper chord 


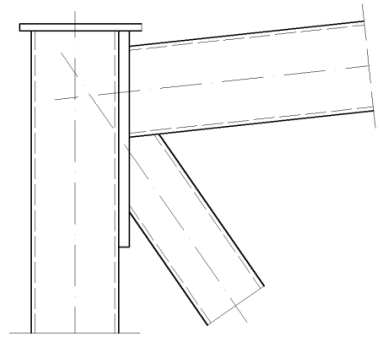

Fig. 6. Eaves joint based on the column at a lower chord level

\section{PRINCIPLES FOR ASSESSING THE RESISTANCE OF JOINTS}

In EN 1993-1-8 the formulas used to assess the resistance of the joints made of hollow sections are provided. These equations are also presented in monographs and handbooks [2], [3], [8], [9]. Their use has been limited to assessing the resistance of the joints only in design situations for small eccentricities in the joints, the class sections (only 1 or 2), the angles between the brace and the chord $(\theta \geq 30)$, the product wall thickness $(\mathrm{t} \geq 2.5 \mathrm{~mm})$, the yield stress material $\mathrm{f}_{\mathrm{y}} \leq 460 \mathrm{MPa}$ (sometimes multiplied by a factor of 0.9 ) and the use of products manufactured according to EN 10210 or EN 10219. This is an area with the most frequent use of hollow section joints. In the case of joints with a mutual overlap of the braces the overlap ratio is determined as:

$$
\lambda_{o v}=(q / p) \cdot 100 \% \text {, }
$$

where:

$q$ the length of overlap, measured at the face of the chord, between one brace member toe and the position of the other projected brace member toe, in joints $\mathrm{K}$ i N (Fig. 7),

$p \quad$ The length of the projected contact area of the overlapping brace member onto the face of the chord, in the absence of the overlapped brace member, in joints $\mathrm{K}$ i N (Fig. 7).

The relationship to determine the gap $\mathrm{g}$ is given by Packer [3]:

$$
g=\left(e+\frac{h_{0}}{2}\right) \frac{\sin \left(\theta_{i}+\theta_{j}\right)}{\sin \theta_{i} \sin \theta_{j}}-\frac{h_{i}}{2 \sin \theta_{i}}-\frac{h_{j}}{2 \sin \theta_{j}},
$$

where:

e - eccentricity of the intersection of the axis of the braces in relation to the axis of the chord, $h_{0}$ - height of the chord wall,

$h_{i}, h_{j}$ - the respective heights of the wall of the overlapping and overlapped brace members

$\theta_{i}, \theta_{j}$ - the respective angles of the overlapping and overlapped braces in relationship to the chord. 


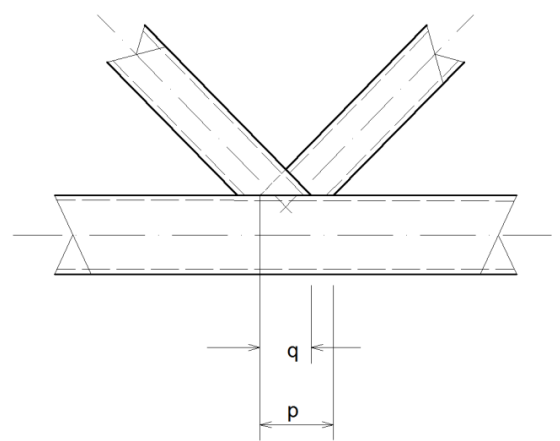

Fig. 7. Overlap ratio

It should be noted that, in the case of mutual overlap of the braces, the eccentricity is negative (Fig. 1a). If the value of $g$ is determined, firstly the eccentricity is [3]:

$$
e=\left(\frac{h_{i}}{2 \sin \theta_{i}}+\frac{h_{j}}{2 \sin \theta_{j}}+g\right) \frac{\sin \theta_{i} \sin \theta_{j}}{\sin \left(\theta_{i}+\theta_{j}\right)}-\frac{h_{0}}{2} .
$$

After determining the dimensions of the joint and the grade of steel the resistance of the joints is checked depending on the ratio $\lambda_{o v}$ in accordance with EN 1993-1-8 [5]:

a) In the case of a square or rectangular hollow sections:

- when $25 \% \leq \lambda_{\text {ov }}<50 \%$ :

$$
N_{i, R d}=f_{y i} t_{i}\left[b_{e f f}+b_{e, o v}+\left(\frac{\lambda_{o v}}{50}\right) 2 h_{i}-4 t_{i}\right] / \gamma_{M 5},
$$

- when $50 \% \geq \lambda_{\text {ov }}<80 \%$ :

$$
N_{i, R d}=f_{y i} t_{i}\left[b_{e f f}+b_{e, o v}+2 h_{i}-4 t_{i}\right\rfloor / \gamma_{M 5},
$$

- when $\lambda_{\text {ov }} \geq 80 \%$ :

$$
\left.N_{i, R d}=f_{y i} t_{i} \mid b_{i}+b_{e, o v}+2 h_{i}-4 t_{i}\right] / \gamma_{M 5},
$$

b) In the case of circular hollow sections:

- when $25 \% \leq \lambda_{o v}<100 \%$ :

$$
\left.N_{i, R d}=0,25 \pi f_{y i} t_{i} \mid 2 d_{i}+d_{e f f}+d_{e, o v}-4 t_{i}\right] / \gamma_{M 5},
$$

- when $\lambda_{o v}=100 \%$ : 


$$
\left.N_{i, R d}=0,25 \pi f_{y i} t_{i} \mid 2 d_{i}+2 d_{e, o v}-4 t_{i}\right] / \gamma_{M 5} \text {, }
$$

where:

$f_{y i}$ - the yield strength of the used steel,

$t_{i}$ - the wall thickness of the overlapping brace,

$b_{\text {eff, }} d_{\text {eff }}$-the effective width or the effective diameter respectively of the overlapping brace in connection to the chord,

$b_{e, o v}, d_{e, o v}-$ the effective width or the effective diameter respectively of the overlapping brace in connection with the overlapped brace,

$b_{i}, d_{i}$-the width or the diameter of the overlapping brace,

$h_{i}$ - the height of the cross section of the overlapping brace,

$\gamma_{M 5}=1,0 .-$ partial safety factor.

Equations (2.4) to (2.6) are given in EN 1993-1-8 [5]. Equations (3.7) and (2.8) are adapted to the symbols used in the Polish and European standards after taking them from IIW Recommendations [6].

$$
\begin{gathered}
d_{e f f}=\frac{12}{d_{0} / t_{0}} \frac{f_{y 0} t_{0}}{f_{y} t_{i}} d_{i} \leq d_{i}, \\
d_{e, o v}=\frac{12}{d_{j} / t_{j}} \frac{f_{y j} t_{j}}{f_{y} t_{i}} d_{i} \leq d_{i} .
\end{gathered}
$$

These formulas relating to the resistance of the welded $\mathrm{K}$ joints may be used if instead of overlap joints; joints with reinforcing ribs are used. Such a suggestion has previously been expressed by some scientists but it is currently being ignored in EN 1993-1-8. However, knowledge of the assessing of the resistance of such joints is still useful. In order to confirm the validity of such procedures an analysis of experimental results conducted in Poland [12] and published in brief in [11] has been carried out. The proposal to assess the resistance of the joints given in these studies is quite complex, while in EN 1993-1-8 it is very simple, although it seems that it is oversimplified. For the purposes of designing relations (2.4) to (2.6) and (2.7) to (2.8) it is more convenient to be less laborious than designs presented in [9] to [11], and also to securely assess the safety of structure. The advantage of the recommendations presented in the Standard is that during their formulation, only 3 models of failure of the joints made of hollow sections were considered and thus the forms of the joints failure were limited, so that only some of these models could appear in the actual construction. In contrast, during determining the design formulas in [10] to [12] nine models of joints' failure were considered. 
Finally, there is a need to assess the resistance of the joints in which mutual overlap is small $\left(\lambda_{\text {ov }}<25 \%\right)$. No experimental studies of such joints have been published and such a situation often occurs in intermediate and support joints. The analysis conducted in section 4 concerns only six intermediate joints, but the result indicates that the recommended procedure for calculation is very safe. In the case of the support joint, they seem to be satisfactory, despite the fact that both the thickness of end plate and the elements of the support (Fig. 5 and 6) result in a higher stiffness of the joints. However, the standard does not assess the scope of their stiffness. So it seems that the assessing of the joints with the reinforcing ribs for gap joints given in tab. 7.2 of EN1993-1-8 [5] is acceptable. If, in the intermediate and support joints, the wall sections are reinforced, the recommendations given in EN 1993-1-8 [5] should be applied with respect to the joints made of square or rectangular hollow sections. However, when such reinforcement is designed in the case of circular hollow sections, this can be done as described in [2], while adopting the recommendations relating to flat walls [5].

\section{EXPERIMENTAL VERIFICATION}

The sample $\mathrm{K}$ joints with the ribs [11] made of square hollow sections were comprised of elements made of British Steel Corporation products and their physical and geometrical properties were at the time consistent with the British Standard. It can be assumed that the steel and sections still fit the current standard EN 10210. The chords were made of sections measuring 100x100 mm with a thickness of $4 \mathrm{~mm}$ or $5 \mathrm{~mm}$, and the braces were made of sections measuring 40x40x3,6 mm, 70x70x3,6 mm, 70x70x5 mm, and 100x100x4 mm. The steel grades corresponded to a nominal yield strength of $f_{y}=275 \mathrm{MPa}$, although the properties of the steel used changed in relation to the section's dimensions from $275 \mathrm{MPa}(100 \times 5 \mathrm{~mm})$ to $300 \mathrm{MPa}(70 \times 3,6 \mathrm{~mm})$.

Also some wall thickness deviations were observed, of $3,55 \mathrm{~mm}, 3,85 \mathrm{~mm}, 4,90 \mathrm{~mm}, 4,25 \mathrm{~mm}$ and 5,20 mm, depending on the nominal values of dimensions. The wall thickness was greater in the corner by approximately $30 \%$ and decreased rapidly towards the value of the flat section. Deviations of dimensions in the sides were minimal. The number of analysed joints was typically 3 units for each type of joint, but in one case six units of the joint were tested, and in the four test elements the additional compression in the chord of the force from $110 \mathrm{kN}$ to $330 \mathrm{kN}$ was given. This was done in the case of braces which were $40 \times 3,6 \mathrm{~mm}$, which during the study had a tendency to bend despite axial longitudinal loading. In three cases, failure occurred through a partial rupture of the welded joint. 


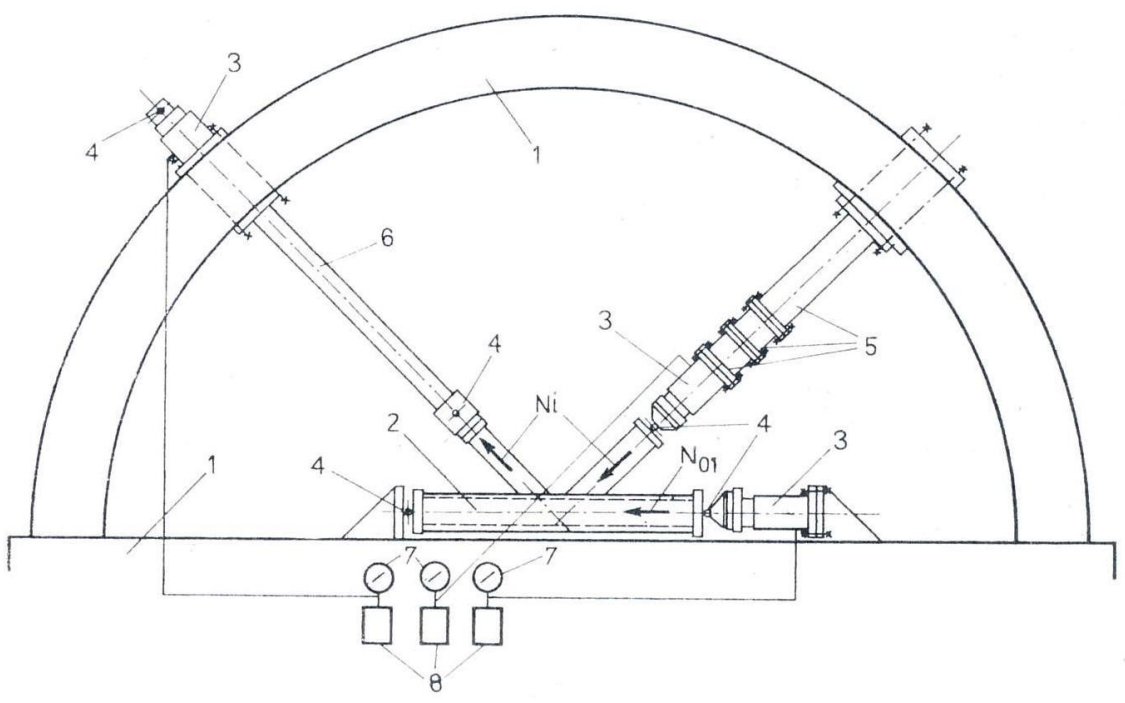

Fig. 8. Test rig

Samples were produced as shown in Fig. 1. Their symbols and dimensions are specified in Table.1

The investigations were conducted by placing the joints in a device that allowed for loading them using the hydraulic actuators. Test rig is shown in Fig. 8. Numbers are: 1 - Stand, 2 - Sample, 3 Jack, 4 - Hinge, 5 - Segment of a strut, 6 - Tie, 7 - Manometer. 8 - Pump. However, it did not always manage to enter the axial force, which occurred to the greatest extent in the compression braces made of $40 \times 3,6 \mathrm{~mm}$ sections.

Table 1. Comparison of the results of experimental research and analytical analysis of the joints

\begin{tabular}{|c|c|c|c|c|}
\hline \multirow{2}{*}{$\begin{array}{c}\text { JOINT } \\
\text { SYMBOL }^{1)}\end{array}$} & \multicolumn{2}{|c|}{ EXPERIMENTAL DATA } & \multicolumn{2}{|c|}{$\begin{array}{l}\text { CALCULATION } \\
\text { according to PN-EN 1993-8 }\end{array}$} \\
\hline & $\begin{array}{c}\text { Ratio } \lambda_{\text {ov }} \\
\%\end{array}$ & $\begin{array}{l}\text { Joint resistance } \\
\text { kN }\end{array}$ & Joint resistance $\mathrm{kN}$ & $\begin{array}{c}\text { Indicator } R_{z, p l} \\
\%\end{array}$ \\
\hline $\begin{array}{l}\text { D45-10-4-4 } \\
\text { D45-10-4-5 }\end{array}$ & $\begin{array}{l}28,29 \\
28,29\end{array}$ & $\begin{array}{l}322 \\
433\end{array}$ & $\begin{array}{l}74,3^{2)} \\
84,2^{2)}\end{array}$ & $\begin{array}{l}332^{2)} \\
332^{2)}\end{array}$ \\
\hline D45-04-2-4 & 35,34 & 132 & $84,3^{2)}$ & $56,7^{2)}$ \\
\hline $\begin{array}{l}\text { D45-07-6-4 } \\
\text { D45-07-6-5 }\end{array}$ & $\begin{array}{l}60,61 \\
60,61\end{array}$ & $\begin{array}{l}200 \\
245\end{array}$ & $\begin{array}{c}193,9^{3)} \\
204,7\end{array}$ & $\begin{array}{l}3,1^{3)} \\
19,5\end{array}$ \\
\hline $\begin{array}{l}\text { D60-10-2-4 } \\
\text { D60-10-2-5 }\end{array}$ & $\begin{array}{l}17,32 \\
17,32\end{array}$ & $\begin{array}{l}368^{4)} \\
447^{4)}\end{array}$ & $\begin{array}{l}159,9^{4)} \\
223,4^{4)}\end{array}$ & $\begin{array}{l}131^{4)} \\
100^{4)}\end{array}$ \\
\hline
\end{tabular}




\begin{tabular}{|c|c|c|c|c|}
\hline \multirow{2}{*}{$\begin{array}{c}\text { JOINT } \\
\text { SYMBOL }^{1)}\end{array}$} & \multicolumn{2}{|c|}{ EXPERIMENTAL DATA } & \multicolumn{2}{|c|}{$\begin{array}{l}\text { CALCULATION } \\
\text { according to PN-EN 1993-8 }\end{array}$} \\
\hline & $\begin{array}{c}\text { Ratio } \lambda_{\text {ov }} \\
\%\end{array}$ & $\begin{array}{l}\text { Joint resistance } \\
\mathrm{kN}\end{array}$ & Joint resistance $\mathrm{kN}$ & $\begin{array}{c}\text { Indicator } R_{z, p l} \\
\%\end{array}$ \\
\hline $\begin{array}{l}\text { D60-07-2-4 } \\
\text { D60-07-2-5 }\end{array}$ & $\begin{array}{l}24,75 \\
24,74\end{array}$ & $\begin{array}{l}231 \\
289\end{array}$ & $\begin{array}{l}167,3 \\
184,6\end{array}$ & $\begin{array}{c}38 \\
56,6\end{array}$ \\
\hline $\begin{array}{c}\text { D60-04-24 } \\
\text { D60-04-2-5 }\end{array}$ & $\begin{array}{l}43,29 \\
43,29\end{array}$ & $\begin{array}{c}170 \\
105^{5)}\end{array}$ & $\begin{array}{c}95,4 \\
105,3^{5)}\end{array}$ & $\begin{array}{l}78,2 \\
0,0^{5)}\end{array}$ \\
\hline $\begin{array}{l}\text { D60-10-6-4 } \\
\text { D60-10-6-5 }\end{array}$ & $\begin{array}{l}51,90 \\
51,90\end{array}$ & $\begin{array}{l}394 \\
479\end{array}$ & $\begin{array}{l}292,6 \\
315,2\end{array}$ & $\begin{array}{l}34,7 \\
52,0\end{array}$ \\
\hline $\begin{array}{l}\text { D60-07-6-4 } \\
\text { D60-07-6=5 }\end{array}$ & $\begin{array}{l}74,26 \\
74,26\end{array}$ & $\begin{array}{l}245 \\
284\end{array}$ & $\begin{array}{l}170,9 \\
188,2\end{array}$ & $\begin{array}{l}43,4 \\
50,1\end{array}$ \\
\hline \multicolumn{5}{|c|}{$\begin{array}{l}\text { 1) Letter D means a joint with a rib; number after the letter D specifies the angle of the braces' inclinations } \\
\text { relative to the chord in degrees; the number after the first hyphen determines the ratio of the width of the } \\
\text { braces to the width of the chord, multiplied by } 10 \text {; the number after the second hyphen gives the length } \\
\text { of the overlap of braces (q) in cm; the third number after the hyphen is the wall thickness of the chord in } \\
\mathrm{mm} \text {. } \\
\text { 2) Resistance in accordance with PN EN 1993-1-8, assuming } \mathrm{f}_{\mathrm{y}}=275 \mathrm{MPa} \text {, while the steel of braces in } \\
\text { tested joints has } \mathrm{f}_{\mathrm{y}}=300 \mathrm{MPa} \text {. } \\
\text { 3) Two joints after the destruction showed the three forms of buckling of the chord walls due to non-axial } \\
\text { load application. } \\
\text { 4) A joint showed a small tilt in the contact area of the braces with the chord, which indicates some shear } \\
\text { web in the area of the chord, which is not included in the PN-EN 1993-1-8. } \\
\text { 5) An additional prestressing force of } 330 \mathrm{kN} \text { was introduced value, which according to PN EN 1993-1-8 } \\
\text { did not affect the form of destruction. }\end{array}$} \\
\hline
\end{tabular}

The joints were shaped in such a way that the braces were inclined with respect to the chord at the same angles of $45^{\circ}$ or $60^{\circ}$. In the case of thoseaxes and when braces having the width of $40 \mathrm{~mm}$ or $70 \mathrm{~mm}$ they intersected at eccentricity $\mathrm{e} \approx-\mathrm{b}_{0} / 3$. Eccentricity e $\approx 0$ occurred in the joints at an angle of $45^{\circ}$ and $\mathrm{b}_{0}=70 \mathrm{~mm}$, and at angles of $45^{\circ}$ or $60^{\circ}$ and $\mathrm{b}_{0}=70 \mathrm{~mm}$ or $100 \mathrm{~mm}$, and the eccentricity e $\approx+b_{0} / 3$ occurred only with $b_{0}=100 \mathrm{~mm}$. Analysing the results of the experiments in [10], [12] the modes of failure of joints were distinguishable and can be characterized in following forms:

- local buckling failure of the chord wall near the tension brace,

- inclination of the chord in the overlap area,

- local buckling of the transverse wall of the compression brace,

- local buckling of the chord wall near the both ends of inclinations,

local buckling as previously mentioned, and additional local buckling of the chord walls on the side of the tension brace,

- inclination of the contact area of the chord without local buckling failure of the walls, 
- inclination of the contact area of the chord with local buckling failure of the web of the chord on the side of tension brace with additional compression,

- inclination as before with local buckling failure of the chord walls on the side of both braces with additional compression. The results of the comparative analysis are presented in Table 1 . The experimental resistance of the joint was determined as the mean of resistance obtained from the tests of a given joint type. An analytical calculation of the joints' resistance conducted assuming that $f_{y i}=f_{y 0}=275 \mathrm{MPa}$ according to requirements of the standard EN 1993-1-8 [5], not taking into account the actual yield strength. The indicator of joints resistance in reserve over the resistance according to EN 1993-1-8 was calculated as follows:

$$
R_{z, p l}=\frac{K_{i u}-N_{i, R d}}{N_{i, R d}} \cdot 100 \%,
$$

where:

$K_{i u}-$ the experimental resistance of the joint,

$N_{i, R d}$ - the resistance of the joint calculated according to PN-EN-1993-1-8.

This indicator includes the effects of the omission of the actual yield strength, as well as the adoption of the design formulas in a very simplified form.

Based on this ratio, it can be concluded that the experimental investigation of the joints with ribs showed great resistance (over 19\%) during the in relation to simple overlap joints without ribs.. Only two joints of a single type showed the $7 \%$ or $11 \%$ experimentally obtained resistance.

\section{CONCLUSIONS}

Determining overlap joints resistance formulas with or without the reinforcing ribs is not easy because of the large differences in the results obtained during both experiments, as well as the calculation. In EN 1993-1-8 [5]. This difficult situation in determining code formulas has already been indicated in [6]. These equations are given in a very simple form, but they make it possible to obtain a safe resistance in the case of joints with reinforcing ribs. Joints with the reinforcing ribs are a useful option when the designer and contractor construction encounter difficulties during manufacturing of the overlapping joint. Obtaining good quality joints is possible in the factories with welding manipulators, enabling easy enough access to the places of welding, especially when this has to be done by cutting through windows. Such activities require employment of highly skilled welders. If there are concerns related to the quality of such welds, the best solution is to design joints with reinforced ribs. 


\section{DESIGN EXAMPLE}

Fig. 9 presents the connection of a bottom chord with two the most loaded CHS braces, made of $\mathrm{S} 275 \mathrm{HN}$, with dimensions and the internal forces showed in figure.

Checking the validity of the equations in accordance with PN-EN 1993-1-8 (Tab. 1):

$0,2<114,3 / 139,7=0,82<1,0 ; \quad 10<139,2 / 12=11,64<50, \quad 10<114,3 / 8,8=13<50$.

Members have class 1 cross-sections. The values of angles presented in Fig. 9 are: $\theta_{j}=42^{\circ} 4^{\prime} 6^{\prime \prime}>30^{\circ}, \theta_{l}=47^{\circ} 7^{\prime} 6^{\prime \prime}>30^{\circ}$.

Trigonometric functions of the angles: $\sin \theta_{j}=0,6700, \sin \theta_{i}=0,7328, \sin \left(\theta_{j}+\theta_{i}\right)=1,0$.

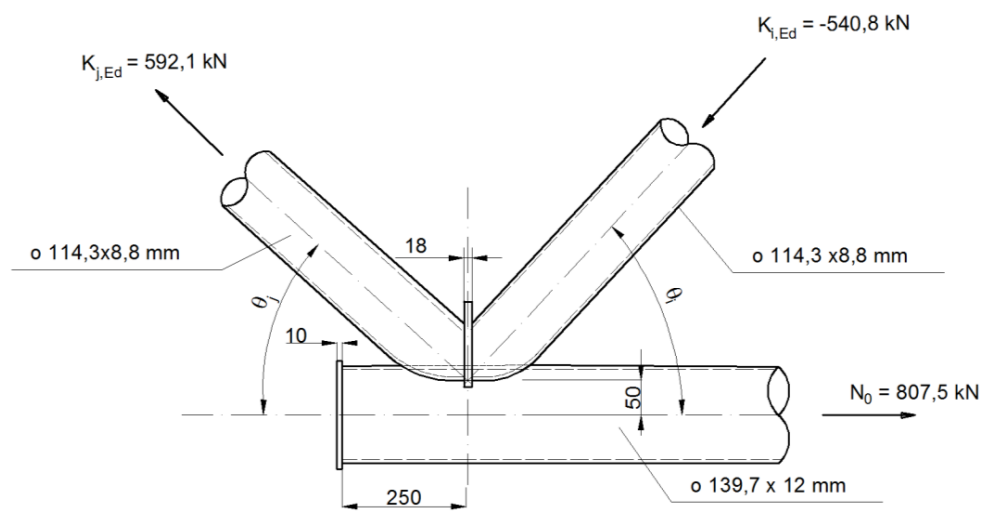

Fig. 9. Extreme joint of the bottom chord

A length of the overlap of the compressed brace on the tension brace according to Packer formula is:

$$
\begin{aligned}
& q=\left(e+\frac{d_{0}}{2}\right) \frac{\sin \left(\theta_{i}+\theta_{j}\right)}{\sin \theta_{i} \sin \theta_{j}}-\frac{d_{i}}{2 \sin \theta_{i}}-\frac{d_{j}}{2 \sin \theta_{j}}= \\
& =\left(-50+\frac{139,7}{2}\right) \frac{1,0}{0,7328 \cdot 0,6700}-\frac{114,3}{2 \cdot 0,7328}-\frac{114,3}{2 \cdot 0,6700}=-122,9 \mathrm{~mm}, \\
& \lambda_{o v}=(q / p) \cdot 100 \%=(122,86 / 155,98) \cdot 100 \%=78,8 \% .
\end{aligned}
$$

The effective lengths of braces:

$$
d_{e j}=d_{e i}=\frac{12}{139,7 / 12} \frac{275 \cdot 12}{275 \cdot 8,8} \cdot 114,3=160,7 \mathrm{~mm}>114,3 \mathrm{~mm} .
$$


Assumed $d_{e j}=d_{e i}=114,3 \mathrm{~mm}$.

$$
d_{e, o}=\frac{12}{114,3 / 8,8} \frac{275 \cdot 8,8}{275 \cdot 8,8} \cdot 114,3=105,6 \mathrm{~mm}<114,3 \mathrm{~mm} .
$$

The resistance of the joint accordingly to IIW Recommendations:

$$
\begin{aligned}
& N_{i, E d}=N_{j, E d}=\frac{3,14}{4} \cdot 275 \cdot 8,8(2 \cdot 114,3+114,3+105,6-4 \cdot 8,8) / 1,0=785,1 \mathrm{kN} \\
& \frac{592,1}{785,1}=0,754<1,0 .
\end{aligned}
$$

The resistance of the joint is sufficient to transfer the loads in braces.

\section{REFERENCES}

1 Bródka J., Broniewicz M.: Steel structures in hollow sections. Arkady. Warszawa 2001 (in Polish).

2 Bródka J., Kozłowski A., Ligocki I., Łaguna J., Ślęczka L.: Design and calculation of joints in steel structures. Vol. 1. Second Edition. PWT. Rzeszów 2013 (in Polish).

3 Packer J. A., Henderson J. E.: Hollow Structural Section Connections and Trusses - A Design Guide. Second Edition. Canadian Institute of Steel Construction. Toronto 1997.

4 Packer J. A., Wardenier J., Zhao X.-L., van der Vegte G. J., Kurobane Y.: Design guide for rectangular hollow section (RHS) joints under predominantly static loading. LSS Verlag. CIDECT. 2009.

5 PN-EN 1993-1-8: 2008 Eurocode 3: Design of steel structures - Part: 1 -8 Design of joints.

6 Puthli R., Ummenhofer Th., Wardenier J., Petermann I.: Anschlüsse mit Hohlprofilen nach DIN EN 1993-1-8. Hintergrund, Kommentare, Beispiele. In „Stahlbau - Kalender 2011“. Herausgegeben von Ulrike Kuhlmann. Ernst und Sohn GmbH. Berlin 2011.

7 Static design procedure for welded hollow section joints. Recommendations. 3rd Edition. International Institute of Welding. Commission XV. IIW. Doc. XV-1129-09.

8 Wardenier J., Kurobane Y., Packer J. A., van der Vegte G. J., Zhao X.-L.: Design guide for circular hollow section (CHS) joints under predominantly static loading. LSS Verlag. CIDECT. 2008.

9 Wardenier J., Packer J. A., Zhao X.-L., van der Vegte G. J.: Hollow sections in structural applications. Bouven met Staal. Zoetemer 2010.

10 Życiński J.: Ultimate resistance of the K-type joint made of rectangular hollow sections. PhD Thesis, Warsaw University of Technology. 1982 (in Polish).

11 Życiński J., Czechowski A., Bródka J.: Ultimate resistance of the K-type joint made of rectangular hollow sections. - The Archives of Civil Engineering. 1986, No 3 (in Polish).

12 The Design-Research Centre of Metal Structures „Mostostal”. Research program coordinated by the Association "Mostostal", financed by public funds. The program of experimental research and development of the results of research conducted under the direction of J. Bródka. 1980-1981 (reports not published). 